\title{
Effect of a Common Mutation (D442G) of the Cholesteryl Ester Transfer Protein Gene on Lipids and Lipoproteins in Children
}

\author{
RINA ARASHIRO, KEISUKE KATSUREN, KYU KYU MAUNG, SHIGERU FUKUYAMA, AND \\ TAKAO OHTA \\ Department of Pediatrics, Faculty of Medicine, University of The Ryukyus, Nishihara, Okinawa 903-0125, \\ Japan [R.A., K.K., S.F., T.O.]; and Department of Pediatrics, Kumamoto University School of Medicine, \\ Kumamoto, Japan [K.K.M.]
}

\begin{abstract}
ABST
Cholesteryl ester transfer protein (CETP) is thought to regu-
late plasma HDL. Patients with CETP deficiency caused by
mutation of the CETP gene [D442G; a missense mutation
(Asp442 $\rightarrow$ Gly)] have been reported to show high plasma HDL
levels. However, there are no data available on children with
D442G. To determine the effects of plasma CETP and CETP
gene mutation (D442G) on lipids and lipoproteins in children, we
screened children by PCR and restriction fragment length poly-
morphism analysis of the CETP gene. Plasma lipids, apolipopro-
teins, and CETP mass levels were also determined. In the current
study, 22 children with D442G were found (21 heterozygotes and
a homozygote). A homozygous child showed high plasma HDL
level and very low plasma CETP mass. In heterozygous children,
plasma concentrations of HDL cholesterol, apo A-I and apo A-II
were not increased, whereas plasma CETP mass was signifi-
cantly decreased. Plasma CETP mass in heterozygous children
was correlated with plasma concentrations of total cholesterol,
\end{abstract}
Esterification of cholesterol from peripheral tissues and subsequent transfer of $\mathrm{CE}$ from HDL to other lipoproteins are key steps in reverse cholesterol transport, i.e. transport from peripheral cells to the liver for excretion $(1,2)$. In humans, extracellular cholesterol is esterified by the action of LCAT, and the $\mathrm{CE}$ generated is transferred to the liver by two known pathways: 1) uptake of HDL particles by the liver $(3,4)$, and 2) uptake of HDL CE by LDL receptor in the liver via transfer of HDL-CE to VLDL and LDL, in a process mediated by CETP $(1,2,5)$. Most LCAT and CETP are associated with HDL particles in human plasma $(6,7)$. Cholesterol esterification in HDL by LCAT increases the size of HDL particles, and the

Received February 8, 2001; accepted April 25, 2001.

Correspondence and reprint requests: Takao Ohta, M.D.,, Faculty of Medicine, University of The Ryukyus, 207 Uehara, Nishihara, Okinawa, 903-0125 Japan; e-mail: tohta@med.u-ryukyu.ac.jp

Supported by Health Sciences Research Grants (Research on Specific Diseases) from the Ministry of Health and Welfare and by Grant-in-aid No13470166 for Scientific Research (B) from The Ministry of Education, Science, Sports and Culture.
LDL cholesterol, and apo B. Plasma CETP mass in children without D442G was not correlated with the plasma concentration of any lipid or apolipoprotein. All of these data suggest that the D442G mutation, by itself, might not affect HDL metabolism in children. The CETP mass required for efficient HDL-cholesteryl ester clearance in children may be less than that in older subjects. (Pediatr Res 50: 455-459, 2001)
CE, cholesterol ester
Abbreviations
CETP, cholesteryl ester transfer protein
HDL-C, HDL-cholesterol
LCAT, lecithin-cholesterol acyltransferase
RFLP, restriction fragment length polymorphism
TC, total cholesterol
TG, triglyceride

transfer of CE from HDL particles reduces the size of HDL. Thus, the size of HDL particles reflects the net rate of CE generation on and CE transfer from HDL particles. Furthermore, we have shown in previous studies that the function of HDL, as well as the particle size, is strongly affected in the presence of LCAT or CETP deficiency $(8,9)$. These findings, taken together, suggest that LCAT and CETP play a central role in maintaining the antiatherogenic nature of HDL.

To date, several common polymorphisms have been reported in the CETP gene (10-12). Most are located within intronic regions and do not appear to affect either the secretion or the function of CETP. Two mutations, an intron 14 splice donor site mutation (Int14A) and a missense mutation within exon 15 (D442G), have been reported in Japanese subjects with high HDL-C levels ( $>100 \mathrm{mg} / \mathrm{dL})(13-15)$. These mutations affect the structure and function of CETP and are prevalent in Japan but very rare in other countries. Because Int14A and $\mathrm{D} 442 \mathrm{G}$ were originally found in subjects with high HDL-C levels, these mutations ought to be responsible for high HDL-C 
levels. However, it is well known that plasma HDL levels are regulated by environmental factors such as alcohol intake and cigarette smoking $(16,17)$. In addition, there are no data available regarding children with these mutations, who seem to be less affected by environmental factors than subjects reported previously. We have recently screened 500 children for CETP gene mutations (Int14A and D442G). No child with Int14A was found in our children screened. Thus, as a first step to clarify the relation between CETP gene mutations and HDL, in the present study we characterized children with the D442G gene mutation.

\section{METHODS}

Subjects. Outpatients at the Departments of Pediatrics, University of the Ryukyus and Kumamoto University School of Medicine, who had visited the respective university hospitals for a routine check-up were screened for CETP gene mutations. Young adults in the present study were students and volunteers from the staff of the Faculty of Medicine, University of the Ryukyus. Venous blood was drawn after an overnight fast. The study protocol had been approved by the ethical committees of the university hospitals, and informed consent was obtained from the parents of all of the children and from the students and volunteers.

Analysis of D442G mutation. CETP gene mutations were analyzed by PCR and RFLP analysis. A 3-mL sample of venous blood was collected in an EDTA-containing tube. After separating plasma by centrifugation, genomic DNA was isolated from blood cells using a PUREGENE DNA isolation kit (Gentra, Minneapolis, MN, U.S.A.). Extracted DNA (100 ng) was used as a template. Exon 15 and flanking sequences were amplified using paired synthetic oligodeoxyribonucleotides complementary to the human CETP gene (18). The primers used to amplify exon 15 and flanking sequences were as follows: for D442G, 5'-GTGTTTACAGCCCTCATGAAC-3' and 5'-AAGCCAAAGTCCATCTCTGCAG-3'. The reaction was carried out in a final volume of $50 \mu \mathrm{L}$ containing $1.5 \mathrm{mM}$ $\mathrm{MgCl}_{2}, 0.3 \mathrm{mmol}$ of each deoxyribonucleotide triphosphate (Nippon Gene, Wako, Japan), $0.3 \mu \mathrm{mol}$ of each primer, and 2.5 $\mathrm{U}$ of Taq DNA polymerase (Nippon Gene). DNA was amplified by 35 cycles of $35 \mathrm{~s}$ of denaturation at $94^{\circ} \mathrm{C}, 45 \mathrm{~s}$ of annealing at $63^{\circ} \mathrm{C}$, and $35 \mathrm{~s}$ of extension at $72^{\circ} \mathrm{C}$. PCR products (287 bp) were digested with TaqI restriction enzyme (Nippon Gene) at $72^{\circ} \mathrm{C}$ for 3-4 h. Digested PCR products were electrophoresed on $8 \%$ polyacrylamide gel. TaqI RFLPs were detected by ethidium bromide staining. The normal CETP gene has two restriction sites for $T a q \mathrm{I}$, and one restriction site is lost in the gene with the D442G mutation. As a result, the D442G homozygote, heterozygotes, and subjects without D442G showed two bands (218 bp and $69 \mathrm{bp}$ ), four bands (218 bp, 69 bp, $41 \mathrm{bp}$, and $28 \mathrm{bp}$ ), and three bands (218 bp, $41 \mathrm{bp}$, and 28 bp), respectively.

Analysis of lipids, apolipoproteins, and CETP mass. Serum levels of TC, TG, and HDL-C were analyzed using an autoanalyzer and enzymatic methods, or by selective precipitation using sodium phosphotungstate and magnesium chloride (19, 20). LDL-cholesterol was calculated as TC - (HDL-C +
$\mathrm{TG} / 5$ ). Similar to the case of adult, the formula for calculating LDL-C is applicable to children (LDL-C calculated by the formula is closely correlated with LDL-C by direct measurement; $n=163, r=0.965, p<0.01$, Okada T, et al., manuscript in preparation). Apolipoproteins (A-I, A-II, and B) were measured by the turbidity immunoassay method (21). CETP mass was measured by the enzyme immunoassay reported by Kiyohara et al. (22)

Statistical evaluation. One-way ANOVA, the MannWhitney $U$ test, and the Pearson correlation coefficient were used to evaluate the data. Differences among groups or correlations with $p<0.05$ were considered to be statistically significant.

\section{RESULTS}

Five hundred children were screened for CETP gene mutations. We found 30 heterozygotes and a homozygote (5-y-old girl) with the $\mathrm{D} 442 \mathrm{G}$ mutation. The incidence of $\mathrm{D} 442 \mathrm{G}$ heterozygosity was $6 \%$ in children. To further characterize these children, children with and without $\mathrm{D} 442 \mathrm{G}$ who were not obese were recalled to the Ryukyu and the Kumamoto University Hospitals; 21 heterozygotes, a homozygote, and 65 children without D442G mutation visited hospitals, and the parents of the remaining refused or ignored our request. None of the children we studied was obese $(100 \%<$ relative body weight $<120 \%$ ) or taking alcohol or drugs affecting lipid metabolism. Based on Tanner criteria, stages of sexual maturity rating in our children were mostly 1-2. As shown in Table 1, plasma CETP mass was significantly lower in both boys and girls who were heterozygous for $\mathrm{D} 442 \mathrm{G}$ than in their counterparts without D442G $(p<0.001$ and $<0.05)$. No significant differences were found in plasma concentrations of lipids and apolipoproteins between heterozygous children and children without D442G. Plasma concentrations of TC, TG, HDL-C, LDL-C, apo A-I, apo A-II, apo B, and CETP mass in the girl who was homozygous for D442G were 251, 54, 110, 130, 224, 36, 85, and $1.3[\mathrm{mg} / \mathrm{dL}$, except for CETP mass $(\mu \mathrm{g} / \mathrm{mL})]$, respectively.

Relationships between plasma CETP mass and other lipoprotein variables. Because no sex-related differences were found in the levels of plasma lipids, apolipoproteins, and CETP mass in the children we studied, we combined the data for boys and girls in the following analysis. As shown in Table 2, a significant relation was found between CETP mass and TC $(r=0.628, p<0.001)$, CETP mass and LDL-C $(r=0.683, p<0.001)$, and CETP mass and apo B $(r=0.584, p<0.001)$. Among children without D442G, no significant correlations were observed between CETP mass and either lipid or apolipoprotein variables (Table 2). To evaluate the effect of aging, we then studied the relationship between CETP mass and lipid and lipoprotein variables in young adults without D442G. As shown in Table 3, plasma concentrations of HDL-C, apo A-I, and CETP mass were significantly higher in women than those in men $(p<0.05$ or $<0.01$ or $<$ 0.001). No significant relationship was observed between CETP mass and either lipid or apolipoprotein variables except for HDL-C in women (Table 4). 
Table 1. Plasma lipids, apolipoproteins, and CETP concentrations in children with (D442G+) and without heterozygote D442G $\left(D 442 G^{-}\right)$

\begin{tabular}{|c|c|c|c|c|}
\hline \multirow[b]{2}{*}{ Variable } & \multicolumn{2}{|c|}{ Boys } & \multicolumn{2}{|c|}{ Girls } \\
\hline & $\begin{array}{l}\mathrm{D} 442 \mathrm{G}- \\
(n=32)\end{array}$ & $\begin{array}{l}\mathrm{D} 442 \mathrm{G}+ \\
(n=10)\end{array}$ & $\begin{array}{l}\mathrm{D} 442 \mathrm{G}- \\
(n=33)\end{array}$ & $\begin{array}{l}\mathrm{D} 442 \mathrm{G}+ \\
(n=11)\end{array}$ \\
\hline $\mathrm{TC}(\mathrm{mM})$ & $4.39 \pm 0.10$ & $4.45 \pm 0.39$ & $4.50 \pm 0.10$ & $4.65 \pm 0.31$ \\
\hline TG $(\mathrm{mM})$ & $0.98 \pm 0.11$ & $0.83 \pm 0.15$ & $0.83 \pm 0.07$ & $1.01 \pm 0.18$ \\
\hline HDL-C (mM) & $1.61 \pm 0.05$ & $1.66 \pm 0.10$ & $1.71 \pm 0.05$ & $1.55 \pm 0.10$ \\
\hline LDL-C (mM) & $2.33 \pm 0.10$ & $2.43 \pm 0.39$ & $2.43 \pm 0.10$ & $2.61 \pm 0.28$ \\
\hline Apo A-I (g/L) & $1.48 \pm 0.04$ & $1.55 \pm 0.08$ & $1.54 \pm 0.03$ & $1.47 \pm 0.07$ \\
\hline Apo A-II $(g / L)$ & $0.33 \pm 0.01$ & $0.33 \pm 0.02$ & $0.32 \pm 0.01$ & $0.31 \pm 0.02$ \\
\hline CETP $(\mathrm{mg} / \mathrm{L})$ & $2.7 \pm 0.1$ & $1.9 \pm 0.2 \dagger$ & $2.6 \pm 0.1$ & $2.0 \pm 0.1 *$ \\
\hline
\end{tabular}

Values are expressed as mean \pm SEM.

$* p<0.05$.

$\dagger p<0.001$

Table 2. Pearson correlation coefficients for CETP versus other lipoprotein variables in children with $(D 442 G+)$ and without heterozygote D442G (D442G-)

\begin{tabular}{lcr}
\hline CETP versus & $\begin{array}{c}\mathrm{D} 442 \mathrm{G}+ \\
(n=21)\end{array}$ & $\begin{array}{r}\mathrm{D} 442 \mathrm{G}- \\
(n=65)\end{array}$ \\
\hline TC & $0.628^{*}$ & 0.159 \\
Log TG & 0.119 & -0.204 \\
HDL-C & -0.209 & -0.033 \\
LDL-C & $0.683^{*}$ & 0.243 \\
Apo B & $0.584^{*}$ & 0.175 \\
Apo A-I & -0.242 & 0.039 \\
Apo A-II & -0.393 & -0.204 \\
\hline
\end{tabular}

$* p<0.001$.

Table 3. Plasma lipids, apolipoproteins, and CETP concentrations in young adults without heterozygote D442G (D442G-)

\begin{tabular}{lcc}
\hline & D442G- Male & D442G- Female \\
\hline Subject $(n)$ & 61 & 42 \\
Age $(\mathrm{y})$ & $24 \pm 1$ & $24 \pm 1$ \\
TC $(\mathrm{mM})$ & $4.47 \pm 0.10$ & $4.65 \pm 0.13$ \\
TG $(\mathrm{mM})$ & $1.15 \pm 0.10$ & $0.90 \pm 0.07$ \\
HDL-C $(\mathrm{mM})$ & $1.66 \pm 0.05$ & $1.92 \pm 0.05 \ddagger$ \\
LDL-C $(\mathrm{mM})$ & $2.20 \pm 0.08$ & $2.40 \pm 0.10$ \\
Apo B $(\mathrm{g} / \mathrm{L})$ & $0.72 \pm 0.03$ & $0.68 \pm 0.03$ \\
Apo A-I $(\mathrm{g} / \mathrm{L})$ & $1.45 \pm 0.03$ & $1.57 \pm 0.04 \dagger$ \\
Apo A-II $(\mathrm{g} / \mathrm{L})$ & $0.31 \pm 0.01$ & $0.29 \pm 0.01$ \\
CETP $(\mathrm{mg} / \mathrm{L})$ & $2.5 \pm 0.1$ & $2.9 \pm 0.1^{*}$
\end{tabular}

Values are expressed as mean \pm SEM.

$* p<0.05$.

$\dagger p<0.01$.

$\ddagger p<0.001$

\section{DISCUSSION}

In the present study, we found that 1) plasma concentrations of HDL-C, apo A-I, and apo A-II were not increased in children who were heterozygous for D442G, 2) plasma CETP mass is significantly decreased in children who are heterozygous for D442G, 3) plasma CETP mass in children who are heterozygous for $\mathrm{D} 442 \mathrm{G}$ is correlated with plasma concentrations of TC, LDL-C, and apo B, and 4) plasma CETP mass in children and young adults without D442G is not correlated with the plasma concentration of any lipid or apolipoprotein except for HDL-C in young adult women.
Table 4. Pearson correlation coefficients for CETP versus other lipoprotein variables in young adults without heterozygote $D 442 G$ (D442G-)

\begin{tabular}{lcc}
\hline CETP versus & $\begin{array}{c}\text { D442G- Male } \\
(n=61)\end{array}$ & $\begin{array}{c}\text { D442G- Female } \\
(n=42)\end{array}$ \\
\hline TC & 0.124 & -0.026 \\
Log TG & -0.025 & -0.027 \\
HDL-C & -0.022 & $-0.343^{*}$ \\
LDL-C & 0.180 & 0.145 \\
Apo B & 0.123 & 0.208 \\
Apo A-I & -0.064 & -0.234 \\
Apo A-II & -0.021 & -0.173 \\
\hline
\end{tabular}

$* p<0.05$.

D442G mutation is prevalent in the Japanese population, but rare in other ethnic groups. In the present study, the rate of D442G mutation was $6 \%$. This value is similar to those in other reports from Japan (15). The site of the D442G mutation is close to the active site of CETP, and the cellular expression of mutant cDNA leads not only to a reduction in CETP secretion but also to a decrease in the specific activity, compared with the wild type (14). In addition, the coexpression of wild-type and mutant cDNAs reduces wild-type secretion and activity, which suggests that the D442G mutation has a dominant role during cellular expression (14). These data in in vitro experiments are apparently consistent with the clinical finding that D442G heterozygotes and homozygotes have similar plasma concentrations of HDL-C whereas D442G heterozygotes have higher plasma HDL-C concentrations than Int14A heterozygotes (their plasma CETP concentration is half of normal and the specific activity of CETP is normal) $(14,15)$. From these results, it seems reasonable to consider that diminished CETP mass and activity caused by D442G mutation could be responsible for the increased HDL-C in subjects with D442G mutation. However, children who are heterozygous for D442G show normal HDL-C concentrations despite a decreased plasma concentration of CETP (Table 1), although a child who is homozygous for D442G has a very high plasma HDL-C concentration $(110 \mathrm{mg} / \mathrm{dL})$. Furthermore, the plasma concentration of CETP in D442G heterozygotes does not correlate with plasma HDL-C, apo A-I, and apo A-II levels (Table 2). In the preliminary study, similar results were obtained in het- 
erozygous young adults with D442G $(n=8)$. Most previous clinical studies on $\mathrm{D} 442 \mathrm{G}$ mutation were conducted in older subjects with a mean age of more than $50 \mathrm{y}(14,15,23)$. As mentioned previously, plasma HDL levels are regulated by many environmental factors as well as genetic factors. Alcohol intake, cigarette smoking, physical activity, and obesity have all been reported to affect plasma HDL levels $(16,17)$. Environmental factors could modify the effect of $\mathrm{D} 442 \mathrm{G}$ mutation on HDL metabolism. Children seem to be less affected by environmental factors. As an obvious example, none of the children we studied was obese or taking alcohol or smoked. Thus, differences in environmental factors may explain our present data. Hegele et al. (24-26) had reported the associations of genomic variations in apo C-III, apo E, angiotensinogen, intestinal fatty acid binding protein, and paraoxonase genes with variations in plasma lipoproteins in children. Different from our study, the associations were stronger in children than in adults. However, similar to our speculation, they concluded relative absence of age-dependent environmental factors could be responsible for the stronger associations. Further studies are needed to clarify the mechanism that underlies the effect of environmental factors on lipoproteingenotype associations.

It has been reported that HDL-CE is transported to the liver by two pathways: a direct uptake pathway, mediated by hepatic scavenger receptor B-I (in humans, CLA-1, CD36, and lysosomal integral membrane protein II analog-1 receptor) $(3,4$, $27,28)$, and an indirect pathway, involving the exchange of HDL-CE for TG in TG-rich lipoproteins by CETP $(1,2,5)$. It is well known that CETP is a key protein in the indirect pathway. Recently, Collet et al. (29) reported that remodeling of HDL by CETP and hepatic lipase leads to the enhanced uptake of HDL-CE by cellular scavenger receptor B-I. This suggests that both direct and indirect pathways are affected in subjects with $\mathrm{D} 442 \mathrm{G}$ mutation. If both pathways do not operate efficiently, plasma HDL ought to increase, as found in older subjects with D442G mutation. However, plasma HDL is not increased in children who are heterozygous for D442G, although plasma CETP mass is decreased. Plasma CETP mass in children who are heterozygous for D442G is correlated with plasma concentrations of TC, LDL-C, and apo B. From the lack of an association between plasma concentrations of CETP and either lipid or apolipoprotein levels in children without D442G and young male adults, and an inverse association between plasma concentrations of CETP and HDL-C in young female adults, the relative importance of the direct uptake and indirect pathways might be different under different in vivo conditions. Judging from higher plasma CETP mass, more CETP mass may be required for efficient reverse cholesterol transport in young female adults. Further studies addressing the role of sexual hormones and plasma lipases on HDL metabolism are needed.

In conclusion, the plasma CETP mass required for efficient reverse cholesterol transport in children must be less than that in older people. When we consider the results in children who are heterozygous for $\mathrm{D} 442 \mathrm{G}$, less than half of the plasma CETP might be required for efficient HDL-CE clearance in children. However, a deficiency in CETP mass for efficient reverse cholesterol transport increases the plasma HDL concentration, even in children, as found in a child who was homozygous for D442G.

Acknowledgments. The authors thank Drs. Toshinobu Matsuura and Toshiya Tamura for their excellent technical advice, and Dr. Ken Matuyama (Fussa Hospital, Tokyo) for referring the child who was homozygous for D442G.

\section{REFERENCES}

1. Reichel D, Miller NE 1985 Pathophysiology of reverse cholesterol transport, insights from inherited disorders of lipoprotein metabolism. Arteriosclerosis 9:785-797

2. Tall AR 1990 Plasma high density lipoproteins: metabolism and relationship to atherogenesis. J Clin Invest 86:379-384

3. Eisenberg S, Oschry Y, Zimmerman J 1984 Intravascular metabolism of the cholesteryl ester moiety of rat plasma lipoproteins. J Lipid Res 25:121-128

4. Glass CK, Pittman RC, Weinstein DB, Steinberg D 1983 Dissociation of tissue uptake of cholesteryl ester from that of apolipoprotein A-I of rat plasma high density lipoprotein: selective delivery of cholesterol to liver, adrenal and gonad. Proc Natl Acad Sci USA 80:5435-5439

5. Eisenberg S 1984 High density lipoprotein metabolism. J Lipid Res 25:1017-1058

6. Cheung MC, Wolf AC, Lum KD, Tollefson JH, Albers JJ 1986 Distribution and localization of lecithin:cholesterol acyltransferase and cholesteryl ester transfer activity in A-I-containing lipoproteins. J Lipid Res 27:1135-1144

7. Marcel YL, McPherson R, Hogue M, Czarnecka H, Zawadzki Z, Weech PK, Whitlock ME, Tall AR, Milne RW 1990 Distribution and concentration of cholesteryl ester transfer protein in plasma of normolipidemic subjects. J Clin Invest 85:10-17

8. Ohta T, Hattori S, Nakamura R, Horiuchi S, Frohlich J, Takata K, Ikeda Y, Saito Y, Matsuda I 1994 Characterization of subspecies of apolipoprotein A-I-containing lipoprotein in homozygotes for familial lecithin:cholesterol acyltransferase deficiency. Arterioscler Thromb 14:1137-1145

9. Ohta T, Nakamura R, Takata K, Saito Y, Yamashita S, Horiuchi S, Matsuda I 1995 Structural and functional differences of subspecies of apoA-I-containing lipoprotein in patients with plasma cholesteryl ester transfer protein deficiency. J Lipid Res 36:696-704

10. Drayna D, Lawn R 1987 Multiple RFLPs at the cholesteryl ester transfer protein (CETP) locus. Nucleic Acids Res 15:4698

11. Zuliani G, Hobbs HH 1990 EcoNI polymorphism in the human cholesteryl ester transfer protein (CETP) gene. Nucleic Acids Res 18:2834

12. Kuivenhoven JA, De Knijff P, Boer JMA, Smalheer HA, Botma GJ, Seidell JC, Kastelein JP, Pritchard PH 1997 Heterogeneity at the CETP gene locus. Influence on plasma CETP concentrations and HDL cholesterol levels. Arterioscler Thromb Vasc Biol 17:560-568

13. Brown M, Inazu A, Hesler CB, Agellon LB, Mann C, Whitlock ME, Marcel YL, Milne RW, Koizumi J, Mabuchi H, Takeda R, Tall AR 1989 Molecular basis of lipid transfer protein deficiency in a family with increased high-density lipoproteins. Nature 342:448-451

14. Takahashi K, Jiang XC, Sakai N, Yamashita S, Hirano K, Bujo H, Yamazaki H, Kusunoki J, Miura T, Kussie P, Matsuzawa Y, Saito Y, Tall A 1993 A missense mutation in the cholesteryl ester transfer protein gene with possible dominant effects on plasma high density lipoproteins. J Clin Invest 92:2060-2064

15. Inazu A, Jiang XC, Haraki T, Yagi K, Kamon N, Koizumi J, Mabuchi H, Takeda R, Takata K, Moriyama Y, Doi M, Tall A 1994 Genetic cholesteryl ester transfer protein deficiency caused by two prevalent mutations as a major determinant of increased levels of high density lipoprotein cholesterol. J Clin Invest 94:1872-1882

16. Freeman DJ, Griffin BA, Holmes AP, Lindsay GM, Gaffney D, Packard CJ, Shepherd J 1994 Regulation of plasma HDL cholesterol and subfraction distribution by genetic and environmental factors. Associations between the TaqI B RFLP in the CETP gene and smoking and obesity. Arterioscler Thromb 14:336-344

17. Hannuksela ML, Liinamaa MJ, Kesaniemi YA, Savolainen MJ 1994 Relationship of polymorphism in the cholesteryl ester transfer protein gene to transfer protein activity and plasma lipoprotein levels in alcohol drinkers. Atherosclerosis 110:35-44

18. Agellon LE, Quinet E, Gillet T, Drayna D, Brown M, Tall AR 1990 Organization of the human cholesteryl ester transfer protein gene. Biochemistry 29:1372-1376

19. Burnstein M, Scholnick HR, Morfin R 1970 Rapid method for the isolation of lipoproteins from human serum by precipitation with polyanions. J Lipid Res 11:583-595

20. Warnick GR, Nguyen T, Albers AA 1985 Comparison of improved precipitation methods for quantification of high density lipoprotein cholesterol. Clin Chem 31:217222

21. Goto Y, Akanuma Y, Harano Y, Hata Y, Itakura H 1986 Determination by SRID methods of normal values of serum apolipoprotein (A-I, A-II, B, C-II, C-III, and E) in normolipidemic healthy Japanese subjects. J Clin Biochem Nutr 1:73-88 
22. Kiyohara T, Kiriyama R, Zamma S, Inazu A, Koizumi J, Mabuchi H, Chichibu K 1998 Enzyme immunoassay for cholesteryl ester transfer protein in human serum. Clin Chim Acta 271:109-118

23. Sakai N, Yamashita S, Hirano K, Menju M, Arai T, Kobayashi K, Ishigami M, Yoshida Y, Hoshino T, Nakajima T 1995 Frequency of exon 15 missense mutation (442D:G) in cholesteryl ester transfer protein gene in hyperalphalipoproteinemic Japanese subjects. Atherosclerosis 24:139-145

24. Hegele RA, Connelly PW, Hanley AJG, Sun F, Harris SB, Zinman B 1997 Common genomic variation in the APOC3 promoter associated with variation in plasma lipoproteins. Arterioscler Thromb Vasc Biol 17:2753-2758

25. Hegele RA, Connelly PW, Hanley AJG, Sun F, Harris SB, Zinman B 1997 Common genomic variants associated with variation in plasma lipoproteins in young aboriginal Canadians. Arterioscler Thromb Vasc Biol 17:1060-1066
26. Hegele RA, Ban MR, Busch CP, Ramsewak S, Ramdath DD 1999 Lipoproteingenotype associations in Trinidadian neonates. Clin Biochem 32:429-437

27. Woollett LA, Spady DK 1997 Kinetic parameters for high density lipoprotein apolipoprotein AI and cholesteryl ester transport in the hamster. J Clin Invest 99:1704-1713

28. Murao K, Terpstra V, Green SR, Kondratenko N, Steinberg D, Quehenberger O 1997 Characterization of CLA-1, a homologue of rodent scavenger receptor BI, as a receptor for high density lipoprotein and apoptotic thymocytes. J Biol Chem 272:17551-17557

29. Collet X, Tall AR, Serajuddin H, Guendouzi K, Royer L, Oliveira H, Barbaras R, Jiang XC, Francone OL 1999 Remodeling of HDL by CETP in vivo and by CETP and hepatic lipase in vitro results in enhanced uptake of HDL CE by cells expressing scavenger receptor B-1. J Lipid Res 40:1185-1193 